\title{
Numerical simulation of natural convection in the air gap of an inclined flat plat thermal solar collector with partitions attached to its glazing
}

\author{
adel laaraba $^{1}$
}

${ }^{1}$ Affiliation not available

November 23, 2020

\begin{abstract}
In this work, the natural convection in the air gap of an inclined solar collector contains partitions attached to its glazing has been studied numerically. The temperatures of the two horizontal walls are constants and different. The two vertical walls are supposed adiabatic. The equations of the problem are solved with the finite volume method, using of the Fluent software. The necessary objective is to study the influence of the partitions (length and number) on the natural convection in the air gap of the solar collector. The obtained results indicate that the presence of the partitions has important influence on the heat transfer with the decreasing of heat losses with natural convection, so improving of the solar collector efficiency. In this study, it reached that the number of partitions must be higher than 10, and their optimal length is $\mathrm{Lp}=0.4$. The presence of the partitions with the optimal values reduces the heat losses by natural convection with $46 \%$.
\end{abstract}

\section{Hosted file}

inclin\&eacute; 4-1.pdf available at https://authorea.com/users/378155/articles/494697numerical-simulation-of-natural-convection-in-the-air-gap-of-an-inclined-flat-plat-

thermal-solar-collector-with-partitions-attached-to-its-glazing 